\title{
Metodologias virtuosas e plausiveis: situando Hasok Chang no debate sobre os valores na ciência
}

\author{
Virtuous and plausible methodologies: situating \\ Hasok Chang in the debate on the values in science
}

\section{Félix Flores Pinheiro* \\ feliks.sm@gmail.com \\ ORCID \\ https://orcid.org/0000-0001- 7318-5294}

Recebido em:30/03/2021

Aceito em:11/10/2021

* Doutor em Filosofia pela UFSC (2021); este trabalho é fruto direto da minha pesquisa em nível de doutorado, motivo pelo qual agradeço à CAPES e ao departamento de Filosofia da UFSC

\section{Resumo}

A constituição axiológica da ciência é um tema clássico na literatura que tem sido enriquecido por praticantes de distintas science studies. Dentre esses praticantes e ao seu modo, Hasok Chang defende um pluralismo epistemológico baseado nas atividades científicas. Tal pluralismo versa sobre as virtudes epistêmicas enquanto finalidades das práticas científicas. Ao fazê-lo, Chang traz insights para as discussões sobre os valores na ciência, ao mesmo tempo em que a complexidade do seu projeto torna difícil compreender exatamente em que sentido ele se posiciona nesses debates. Este artigo esboça alguns sentidos em que a abordagem que Chang tem formulado pode ser situada no campo.

Palavras-Chave: Hasok Chang. Progresso Científico. Virtudes Epistêmicas.

\section{Abstract}

The axiological constitution of science is a classic theme in the literature that has been enriched by practitioners of different science studies. Among these practitioners and in his own way, Hasok Chang defends an activities-based epistemological pluralism on science. Such pluralism deals with epistemic virtues as goals of scientific practices. In doing so, Chang brings insights into discussions about values in science, while the complexity of his project makes it difficult to understand exactly how he stands in these debates. This article outlines some directions in which Chang's approach can be situated in the field.

Key-words: Hasok Chang. Scientific Progress. Epistemic Virtues. 


\section{Introdução}

"De que serve a terra à vista, se o barco está parado?"

Maria Bethânia. ${ }^{1 \mathbb{}}$

Godfrey-Smith (2003, p. 83) lembra que, para Kuhn, grande parte do segredo do sucesso da ciência está na manutenção de um certo equilíbrio: um balanço notável entre a manutenção e o questionamento da tradição, da proteção de certas compreensões compartilhadas que resiste em alterar as suas noções, mas que não é tão resistente assim. Como se sabe, Kuhn pensava que esse jogo envolve e é mantido por uma coleção de características avaliativas que expressam uma "mentalidade científica". ${ }^{2}$ Destaca-se, no entanto, que "para Kuhn, esse delicado equilíbrio não é algo que possamos descrever em termos de um conjunto de regras explícitas" (Godfrey-Smith, 2003, p. 83). O balanço entre a proteção da tradição, do que é padronizado, e a busca por progresso envolve ao menos dois grandes tópicos sobre os valores e as virtudes científicas. ${ }^{3}$ A saber: 1) a capacidade de se identificar e explicitar certas regras, normas ou características da ciência que expliquem o sucesso desse equilíbrio; 2) o estatuto social e cognitivo de cada uma delas, bem como o seu caráter constitutivo no empreendimento científico. Ambos os tópicos dividem defensores e opositores no crescente universo de debates sobre a constituição axiológica da atividade científica. Eles também aparecem em abordagens que tangenciam uma discussão estrita da axiologia da ciência, seja das teses do seu caráter constitutivo ou da sua neutralidade. ${ }^{4}$ Penso que esse seja o caso, por exemplo, das abordagens de van Fraassen (2007) e de Chang $(2004,2012)$. O objetivo geral do presente artigo é mostrar como isso ocorre em relação ao último. ${ }^{5}$

Pensando no público que desconhece o autor-tema deste artigo, abro um parêntese biográfico. Hasok Chang é um historiador e filósofo da ciência sul-coreano. É professor do Departamento de História e Filosofia da Ciência da Universidade de Cambridge e membro do comitê da Integrated History and Philosophy of Science - \&HPS. A \&HPS é um grupo internacional de acadêmicos que se dedicam à história e a filosofia da ciência de maneira integrada. Como dito por Mendonça (2012), embora interessante e controverso, esse projeto sobre a produção de conhecimento genuinamente científico através da aliança entre ciência, história e filosofia, não é muito conhecido. ${ }^{6}$ Essa produção se dá ao avançar e manter investigações que a própria ciência (strictu sensu) não realiza, motivo pelo qual o projeto acadêmico de Chang (2004) é denominado por "ciência complementar". Em suma, essas investigações possuem os objetivos de produzir, compreender e manter o conhecimento científico, inclusive reconstruindo experimentos realizados ao longo da história e que, por algum motivo, são considerados obsoletos. A título de exemplo, vale mencionar os experimentos

$1 \rrbracket$ Versão da canção "Quem me leva os meus fantasmas" reinterpretada por Maria Bethânia em "Carta de Amor", Gravadora Biscoito Fino, 2013. Composição original de Pedro Machado Abrunhosa, álbum "Luz” - Universal Music Portugal, 2007.

2 Como explica Bird (2018), Kuhn identifica cinco características que proporcionam uma área compartilhada da avaliação e escolha entre teorias: precisão, consistência (interna e externa), escopo, simplicidade e fecundidade. Embora sejam virtudes constitutivas da ciência, cujo abandono completo resulta no abandona da própria atividade científica, essas virtudes não são redutíveis a um conjunto de regras explícitas que determinam as escolhas científicas. Há ao menos três motivos para isso: elas são disputáveis enquanto critérios epistemológicos; elas são imprecisas no sentido de haver espaço para a interpretação e discussão dos seus significados e níveis; finalmente, elas podem entrar em conflito entre si.

3 Neste artigo, os termos "valor" e "virtude" estão sendo utilizados de maneira intercambiável.

4 Em sentido geral, o tema dos valores na ciência divide defensores e opositores do "ideal livre de valores" - a tese de que cientistas devem minimizar a influência de valores contextuais em suas investigações e na avaliação do conhecimento produzido. Relacionado, há uma divisão com relação à "tese da neutralidade axiológica da ciência": cientistas podem, ao menos em princípio, obter evidência, avaliar e aceitar teorias sem utilizar valores contextuais. Por detrás disso, há posturas divergentes com relação ao caráter imprescindível dos valores na compreensão da produção do conhecimento científico, na qual se discute a dicotomia entre valores cognitivos (genuinamente epistêmicos) e valores não-cognitivos (contextuais). Veja-se Reiss e Sprenger (2020).

5 A direção em que as propostas de van Fraassen encontram o debate sobre os valores da ciência é apenas mencionada neste artigo. Para uma discussão mais aprofundada sobre isso, veja-se as respostas de van Fraassen (2007) sobre o assunto.

6 Sobre o caráter polêmico da \&HPS, veja-se a seção 5 do verbete "Historicist Theories of Scientific Rationality" escrito por Nickles (2021). 
e as considerações sobre o calórico, sobre o flogisto, bem como a análise de termômetros e da história da termometria - como os relatórios de Joseph-Louis Gay-Lussac de 1812 e o termômetro de Beckmann (cf. Chang, 2007).

Os trabalhos de Chang $(2004,2012)$ têm recebido grande destaque na filosofia da medição e na filosofia da química, sobretudo a partir de dois livros. ${ }^{7}$ Nessa última área, a abordagem de Chang em "Is Water $\mathrm{H}_{2} \mathrm{O}$ ?” (2012) ofereceu contribuições reconhecidamente notáveis. Homenageada em 2013 com o Fernando Gil International Prize for the Philosophy of Science e em 2015 com a medalha Wilkins-Bernal-Medawar da Royal Society, a obra versa sobre a história da molécula da água e as implicações dessa para uma compreensão filosófica da natureza do conhecimento científico. Dentre essas implicações, destaco haver uma discussão sobre diferentes formas de "realismo científico" e a argumentação em favor do "realismo ativo" defendido pelo autor. Essa argumentação complementa um projeto epistemológico pluralista desenvolvido em seus trabalhos anteriores. ${ }^{8}$ Esse projeto ganhou corpo em "Inventing Temperature" (Chang, 2004), magnum opus sobre os aspectos históricos e filosóficos da termometria, recebedora do Prêmio Lakatos da London School of Economics (LSE) em 2006.

Fechado esse parêntese biográfico, a menção ao pensamento de Kuhn ajuda a nortear alguns pontos discutidos a partir daqui. A discussão caminha através da seguinte questão colocada por ele:

não é que os cientistas descobrem a verdade a respeito da natureza, nem que eles se aproximam ainda mais da verdade. A não ser, como sugere um dos meus críticos, que definamos simplesmente o enfoque da verdade como o resultado da atividade dos cientistas, não podemos reconhecer o progresso na direção dessa meta. Precisamos antes explicar por que a ciência - nosso exemplo mais seguro de conhecimento sólido - progride, e precisamos descobrir primeiro como de fato o faz. (1979, p. 28).

A abordagem de Chang (2004) visa, dentre outros assuntos, explicar em que sentido a ciência progride. Para isso, o autor junta algumas teses epistemológicas pluralistas e baseadas em atividades com uma forma de realismo enquanto atitude - o realismo ativo. $\mathrm{O}$ realismo ativo é, ao invés de uma tese descritiva, uma postura sobre os objetivos da ciência: o compromisso com a busca por conhecimento, tanto nos termos de explicação, como de adequação empírica (cf. Chang, 2018, p. 31). A questão dos valores na ciência e das virtudes epistêmicas aparecem naturalmente através desse pluralismo: elas são as finalidades das atividades científicas, sejam vinculadas com a adequação empírica, ou com a explicação e a inteligibilidade da ciência.

Isso posto, o texto que segue efetua uma aproximação entre o pensamento de Chang (2004) e os tópicos sinalizados acima. ${ }^{9}$ Em específico, eu discuto em quais sentidos é preciso situar o projeto de Chang (2004) com relação à capacidade de se identificar e explicitar características que expliquem o sucesso da ciência; bem como o estatuto constitutivo das mesmas no empreendimento científico. Argumento que essa situação é espontaneamente motivada pelo pluralismo epistemológico marcadamente defendido pelo autor após 2004, mas que é parte integral do seu projeto desde antes disso (ao menos desde 2001) e que deverá estar ainda mais explícita em seus trabalhos futuros. Considerando que a sua abordagem ainda está em desenvolvimento e que há investigações futuras já anunciadas, a discussão aqui fomentada consiste em um esboço, um recorte elucidativo que deverá ser complementado após as suas novas publicações. ${ }^{10}$ Menciono ainda

7 Para uma introdução aos campos das filosofias da medição e da química, veja-se os verbetes escritos por Tal (2020) e por Weisberg, Needham e Hendry (2019), respectivamente.

8 Para uma apresentação introdutória do realismo ativo de Chang, veja-se Vaz (2019).

9 A motivação para situar Chang (2004) na área advém do artigo "Situando Longino no debate sobre os valores na ciência" de Faria (2017). Contudo, minha abordagem para essa situação difere da do autor. Faria (2017) contrasta o pensamento de Longino em relação às teses sobre a distinção entre valores cognitivos e sociais. Esse não será o ponto aqui uma vez que Chang (2004) não adentra diretamente aos temas da axiologia da ciência, embora esboce teses sobre o caráter social da ciência e a relação entre ciência e sociedade (cf. Chang, 2012). Meu intuito é mostrar, por outra via, que o seu projeto avança ao mesmo tempo por distintas frentes no campo das virtudes da ciência.

10 O caráter de esboço deste artigo é muito importante e precisa ser destacado. Ao longo das décadas, a abordagem filosófica de 
que essa aproximação é uma via de mão-dupla frutífera. Ao mesmo tempo em que alguns pontos do seu projeto fornecem insights relevantes para a axiologia da ciência, os argumentos de Chang (2004) utilizam substancialmente defesas sobre o estatuto epistemológico das virtudes na ciência, como veremos. Assim, a sua inserção nos atuais debates sobre os valores científicos destina-se a iluminar uma parte imprescindível do seu projeto. Antes de tudo, é preciso salientar alguns dos aspectos centrais da abordagem de Chang.

\section{Iterações Epistêmicas: coordenação e desenvolvimento científico}

As medições científicas e a prática experimental são os principais estudos de casos de Chang (2007). Dentre as motivações esclarecidas por ele para isso, destaco que a medição quantitativa é uma parte integral da ciência, uma área em que há claros sinais de desenvolvimento, sobretudo através de questões-chave na busca por justificação do conhecimento científico. Uma dessas questões versa sobre a coordenação entre aspectos teóricos e experimentais. Como diz van Fraassen, qualquer teoria "permaneceria um pedaço de matemática pura, ao invés de uma teoria empírica, se seus termos não estivessem ligados a procedimentos de medição. Mas o que é essa ligação?” (2008, p. 115). “Coordenação" é o conceito central no tema da conexão entre regularidades empíricas e representações matemáticas, usualmente na forma de equações. Como explica Luchetti, "o tema da coordenação é um problema epistêmico clássico versando sobre como nós justificamos o uso de ferramentas conceituais abstratas para representar fenômenos concretos" (2020, p. 5).

Uma contribuição recente na história do tema da coordenação foi colocada por Chang (2004): o centro do problema está em uma circularidade qualificada como viciosa entre os componentes conceituais e os procedimentos de medição. Essa circularidade consiste em uma versão, um caso especial, dos problemas de coordenação na prática científica - denominado por ele de "problema da medição nômica":

o problema da circularidade na tentativa de justificar um método de medição que se baseia em uma lei empírica que conecta a grandeza a ser medida com outra grandeza que é (mais) diretamente observável. A verificação da lei exigiria o conhecimento de vários valores da grandeza a ser medida, a qual não pode ser obtida com segurança sem confiança no método de medição. (CHANG, 2004, p. 256).

A partir disso, van Fraassen (2008) e Tal (2020) exploram revisões da questão da coordenação das medições científicas, colocando-a na forma do seguinte problema: como responder ao par de questões "o que é $\mathrm{x}$ " e "o que conta como procedimento de medida apropriado para medir $\mathrm{x} .{ }^{11}$ A questão pode ser elucidada investigando como chegamos a ter boas teorias sobre um alvo e como formulamos bons testes e experimentos sobre essa teoria em relação a esse alvo: boas teorias pressupõem uma harmonia com bons testes; bons

Chang (2001) tem se alterado e se aprimorado. Recentemente ele tem fornecido definições operacionais (frise-se: provisórias) para os conceitos utilizados. O projeto, assim, está em curso e inacabado. Em vista disso, por vezes, o autor pede que essas definições não sejam ainda citadas - dentre elas, a definição de "coerência" para um sistema de práticas (cf. 2017, p. 109). É nesse sentido que o presente artigo deve ser visto como um recorte: uma seleção de passagens através das décadas de um trabalho que está em desenvolvimento e muito próximo de receber um acréscimo significativo no seu já anunciado "Realism for realistic people" (Chang, 2018).

11 Ilustrando o ponto com um exemplo sinalizado por Cartwright e Chang (2008), afirmar que um teste para o quociente de inteligência - o QI, realmente mede aquilo a que ele se propõe (isto é, a grandeza em alvo, aqui abreviada simplesmente por "QI") pode envolver a premissa tácita de que o QI é independente do seu teste. Essa suposta independência acarreta em dificuldades para formular e avaliar tanto o conceito quanto o procedimento. Seguindo a discussão de Cartwright e Runhardt (2014), para que o QI seja um conceito quantitativamente tratável, o mesmo precisa ser identificado, categorizado, vinculado com ao menos um esquema quantitativo que representa adequadamente o seu comportamento e, finalmente, operacionalizado harmoniosamente com esses elementos representativos. Ou seja, cumprir passos do estabelecimento de uma teoria sobre o QI que seja empiricamente e operacionalmente significativa. A teoria será significativa nesses sentidos em vista de certa harmonia experimental, isto é, através do encaixe de algumas das suas asserções e hipóteses com testes detalhados. Esses testes, por sua vez, requerem conhecimentos sobre o comportamento do que está em alvo para que sejam avaliados, para que a qualidade dos seus resultados seja adequadamente compreendida. Aparentemente, isso só pode ser feito uma vez que há um entendimento da correta representação quantitativa sobre o QI, a qual por sua vez só é significativa em vista das próprias operações. 
testes pressupõem avaliações a partir de certo conhecimento teórico, havendo assim uma circularidade ou um regresso ao infinito. ${ }^{12}$

Há ao menos duas estratégias epistemológicas frente a isso. Por um lado, pode-se adotar uma análise de índole fundacionalista. Por outro lado, pode-se argumentar que a circularidade aparentemente viciosa é, pelo contrário, virtuosa. Grande parte da literatura filosófica atual sobre as medições científicas adota essa última via (cf. Tal, 2013, p. 1162). Van Fraassen (2008), por exemplo, argumenta que o que conta como um procedimento de medida para uma grandeza e o que é essa grandeza são questões que sequer fazem sentido quando separadas. Para ele, a justificação desses procedimentos parece falhar apenas se visamos um ponto de partida estável, se a colocarmos desde um ponto de vista fundacionalista (cf. van Fraassen, 2008, p. 137). Como levantado por Chang (2004), é através dessa circularidade que refinamentos prático-teóricos ocorrem, formando um processo virtuoso de recoordenação entre o experimental e teórico. Segundo o autor, "a única maneira produtiva de lidar com essa circularidade é aceitá-la e admitir que a justificação na ciência empírica deve ser coerentista" (Chang, 2004, p. 220).

Como estudos de casos, pode-se encontrar diferentes problemas de coordenação no desenvolvimento histórico das medições para a temperatura, isto é, na história da termometria (cf. Chang, 2004, p. 4). Considerese, por exemplo, a questão sobre como sabemos o que termômetros discordantes entre si nos informam sobre a temperatura do que está em alvo, como no estudo detalhado por Gabriel Lamé em 1836. Aqui, os termômetros com diferentes líquidos fornecem indicações discrepantes, mesmo quando graduados da mesma maneira em relação à fusão e ebulição da água; como pode ser visto nos valores assinalados na Tabela 1.

Tabela 1. Discrepâncias entre termômetros.

\begin{tabular}{c|c|c} 
Mercúrio & Álcool & Água \\
$0^{\circ}$ & $0^{\circ}$ & $0^{\circ}$ \\
\hline $25^{\circ}$ & $22^{\circ}$ & $5^{\circ}$ \\
\hline $50^{\circ}$ & $44^{\circ}$ & $26^{\circ}$ \\
\hline $75^{\circ}$ & $70^{\circ}$ & $57^{\circ}$ \\
\hline $100^{\circ}$ & $100^{\circ}$ & $100^{\circ}$ \\
\hline
\end{tabular}

Fonte: Gabriel Lamé - Cours de physique de l'E'cole Polytechnique (1836, apud Chang, 2004, p. 58)

O problema em questão consiste em compreender o que essas discrepâncias significam. Isso envolve estabelecer teorias e princípios sobre as grandezas em alvo, isto é, dizer como a temperatura se comporta através de diferentes meios. Contudo, a teoria não pode ter suas asserções e hipóteses testadas sem que haja algum instrumento ou dispositivo considerado confiável para tal. Volta-se à questão sobre o que é um bom termômetro em detrimento dos outros, sobre o significado das discrepâncias em função das suas virtudes: uma forma para medir que administre exatidão, precisão, estabilidade, dentre outras características. Chang (2004) questiona em que sentido uma abordagem fundacionalista poderia explicar esse cenário e, argumentando que não é possível traçar uma cadeia justificativa até a natureza, ela se mostra insuficiente. ${ }^{13}$ Então, "na

12 Nesse sentido, o tema da coordenação das medições científicas é um local de destaque na filosofia da ciência atual, pois convergem a ele diferentes versões do problema da indução e diferentes teses da subdeterminação na ciência. Sobretudo, ele envolve de maneira sui generis (quiçá aparente) o paradoxo entre a pressuposição teórica da experimentação e o caráter objetivo do conhecimento científico: para que as medições sejam bem formuladas e executadas, elas precisam ser encaixadas harmoniosamente com o conhecimento de fundo, pressupondo-o desde a sua construção; para que as teorias sejam empiricamente significativas e testadas, as suas medições parecem requerer certa independência.

13 De modo breve, esses questionamentos são: de que maneira uma porção de fenômenos pode ser considerada regular sem que haja um esquema teórico estabelecido previamente? Se o teste do desempenho dos instrumentos, como os termômetros, depende de regularidades empíricas, como essas regularidades são estabelecidas e testadas em vista dos dados fornecidos por um termômetro? Como avaliar que uma escala está sendo aplicada com sucesso a novos âmbitos sem padrões teóricos pré-concebidos sobre as novas extensões da escala? Como testar a correção das formulações das grandezas, como os conceitos 
ausência de quaisquer fundamentos óbvios auto justificados, não temos outra escolha a não ser continuar procurando a justificação. Essa perseverança só pode nos levar ao coerentismo" (Chang, 2004, p. 223).

Chang (2004) argumenta que uma abordagem coerentista possui o lucro de pressupor um certo background, um sistema de conhecimento já estabelecido, embora imperfeito, cujas relações serão o objeto de estudo. Uma dificuldade geralmente atribuída às teorias coerentistas da justificação consiste em estabelecer, junto da noção de "coerência" utilizada, um caráter não estático ao sistema de conhecimento analisado. Isto é, fomentar uma abordagem diacrônica, ao invés de sincrônica. Visando superar essa dificuldade, Chang (2004) argumenta em favor de uma epistemologia coerentista e progressiva, que mantenha e explique certas intuições sobre o progresso científico. A ideia geral já foi sinalizada: ao invés de viciosamente circular, a prática científica é composta por múltiplos elementos teóricos e experimentais que estão em relações virtuosas de suporte mútuo. Ademais, através de substituições nas peças desses sistemas ocorre uma forma de desenvolvimento, a formação de iterações com variados elementos epistêmicos. De acordo com Chang, uma

iteração epistêmica é um processo no qual estágios sucessivos de conhecimento, cada qual construído com base no anterior, são criados a fim de aprimorar o alcance de certos objetivos epistêmicos [...]. Em cada etapa, o estágio posterior é baseado no estágio anterior, mas não pode ser deduzido dele em qualquer sentido direto. Cada elo é baseado no princípio do respeito e no imperativo do progresso, e toda a cadeia exibe um progresso inovador dentro de uma tradição contínua. (2004, p. 226).

O caráter progressivo das iterações epistêmicas na ciência envolve dois problemas prima facie distintos: "como podemos dizer que realmente sabemos o que sabemos? Como poderemos saber mais e melhor do que antes?" (2004, p. 233). Essa divisão envolve o conceito de justificação e o conceito de progresso, requisitando que as iterações sejam efetivamente epistêmicas. Caso não sejam, o sistema inicial não será um sistema de conhecimento e ao invés de progresso haverá alguma outra forma de desenvolvimento. ${ }^{14}$ Para isso, Chang (2004) salienta que as iterações ocorrem em função de objetivos que são, eles mesmos, epistemológicos: o aprimoramento de virtudes epistêmicas. Quais virtudes? Todas elas!

Preocupado com alguma característica cuja exclusão seja contraproducente para o desenvolvimento científico, Chang (2004) avança uma forma de pluralismo epistemológico com relação aos objetivos das investigações científicas e das virtudes epistêmicas relevantes para a ciência. Entretanto, a questão do estatuto epistemológico das virtudes científicas, ou cognitivas, é um problema recorrente face às teses da subdeterminação das teorias (ou hipóteses) pelas evidências (cf. Faria, 2017). Ao invés de fechar essa lacuna, os desenvolvimentos mais recentes da abordagem de Chang $(2016,2017)$ a tangenciam ao enfatizar que as iterações epistêmicas não são sistemas linguísticos. Nesse sentido, a compreensão do conhecimento científico proposta por ele está para além do que pode ser capturado pelos debates sobre como devemos interpretar as teorias científicas, bem como das características definidoras do conhecimento proposicional (sobretudo, a verdade).

Exemplificando, ao invés de analisar as teorias, o ato de teorizar se torna um objeto de estudo analítico. Para isso, o autor esclarece dois conceitos. A saber, uma atividade epistêmica é "um conjunto mais ou menos coerente de operações mentais ou físicas que se destinam a contribuir para a produção ou melhoria do conhecimento de uma forma particular, de acordo com algumas regras discerníveis" (2017, p. 106). Na prática científica, contudo, essas atividades não são isoladas - elas formam sistemas de práticas: "um conjunto coerente de atividades epistêmicas realizadas com o objetivo de atingir certos objetivos” (2017a, p. 106). Reiterando: esses objetivos consistem no aprimoramento de virtudes epistêmicas dentro de um contexto.

de temperatura, estabelecendo uma correspondência entre essa e uma operação física a partir de uma teoria que, por sua vez, também requer verificações através dos resultados de um procedimento de medida?

14 Utilizo a distinção terminológica entre "progresso" e "desenvolvimento" colocada por Niiniluoto (2019): o conceito de "progresso" é uma noção axiológica e normativa, enquanto "mudança" e "desenvolvimento" são noções descritivas que não estão necessariamente vinculadas com o aprimoramento da "boa" ciência. 
Esse é um primeiro sentido em que o pluralismo de Chang (2004) precisa ser situado no debate sobre os valores na ciência. Outros dois sentidos são os seguintes. De caráter historicista e convencional, a pluralidade dos objetivos que se abrem para a promoção do desenvolvimento científico nem sempre são determinadas pelo objeto de estudo, embora sejam sempre relativas a uma tradição. Há, assim, liberdade na escolha do tema, da tradição e dos próprios objetivos. Essa liberdade, contudo, encontra um segundo tópico, de caráter ontológico. Enquanto os fins podem ser convencionalmente estabelecidos, as atividades que os alcançam possuem aspectos constitutivos. Essas atividades investigativas fazem parte de compreensões culturais compartilhadas por uma tradição, apoiadas em regras não empíricas, embora discerníveis, relacionadas com a inteligibilidade da própria ciência: princípios ontológicos (cf. Chang, 2004, p. 91).

Um princípio ontológico é uma asserção de fundo assumida sobre as "características essenciais da realidade por uma comunidade epistêmica, a qual forma a base da inteligibilidade [...] [cuja] justificação [...] não é lógica tampouco advém da experiência" (Chang, 2004, p. 256). Assim, as iterações epistêmicas são partes em um programa filosófico amplo, o qual utiliza virtudes epistêmicas para nortear as práticas científicas bem como para captar e explicitar certos princípios que as constituem. A ênfase na constituição inteligível das atividades científicas, sobretudo aquelas que são "pretendidas para contribuir com a produção ou aprimoramento do conhecimento em uma maneira particular, em acordo com algumas regras discerníveis" (Chang, 2011, p. 209), reúne uma epistemologia que enfatiza as atividades com uma postura realista sobre os objetivos da ciência. Portanto, a abordagem de Chang (2004) adentra ao debate sobre os valores na ciência envolvendo: 1) o estatuto epistemológico do seu pluralismo sobre os objetivos da ciência; 2) a ênfase analítica nas atividades científicas frente a esses objetivos; 3 ) a constituição da inteligibilidade dessas atividades. Também por motivos de espaço, a partir daqui desenvolvo um pouco mais o ponto 1 - apenas mencionando outros tópicos relacionados para motivar trabalhos futuros.

\section{Agentes, Metodologias, Processos e Produtos Virtuosos}

O exposto até aqui pode ser sintetizado no seguinte recorte explicativo fornecido pelo próprio autor:

iteração epistêmica é o método central do coerentismo progressivo. No framework de um coerentismo, a investigação deve proceder com base na afirmação de algum sistema de conhecimento existente. [...] Iniciar por um sistema de conhecimento existente significa construir nas conquistas reais de algum grupo passado de seres inteligentes. Isso confere ao progresso do conhecimento um caráter inexoravelmente histórico e, ironicamente, um caráter também conservativo. Ao mesmo tempo, a conservação da iteração epistêmica é fortemente temperada por um inerente pluralismo. Há vários aspectos com respeito a esse pluralismo. Temos liberdade para escolher qual sistema de conhecimento existente será afirmado como nosso ponto de partida. O grau e a profundidade da afirmação também dependem de nós. Talvez mais importante, a afirmação de um sistema existente não fixe completamente a direção do seu desenvolvimento. $O$ ponto não é meramente que não sabemos qual a direção correta desse desenvolvimento, mas de que talvez sequer haja tal coisa como a correta direção ou mesmo a melhor direção do desenvolvimento. O desejo de realçar diferentes virtudes epistêmicas pode nos levar a diferentes direções de progresso, uma vez que realçar uma virtude pode vir ao preço de sacrificar outra [...] [e] cada linha de investigação precisa ocorrer dentro de uma tradição [...]. A metodologia da iteração epistêmica permite o florescimento de tradições concorrentes, cada uma das quais pode progredir em sua própria base, sem precisar ser sempre julgada em relação às outras. $O$ progresso científico requer tradição e permite liberdade ao mesmo tempo. (CHANG, 2007, p. 20).

Nesse cenário, Chang afirma que está "definindo progresso de uma maneira pluralista: o aprimoramento de qualquer característica que é geralmente reconhecida como uma virtude epistêmica constitui progresso científico" (2004 p. 228, grifo meu). Esse é um primeiro desafio para situar a abordagem de Chang (2004) no 
debate sobre os valores da ciência: quais virtudes que são geralmente reconhecidas como epistêmicas e que efetivamente se encaixam em sua proposta?

Tradicionalmente, o tema envolve certas características que são qualificadas enquanto regras, normas, valores, virtudes, ou heurísticas - como defende Longino (2017) - das práticas de obtenção, justificação e aprimoramento do conhecimento científico. Observando a literatura, é útil organizar essas características em três grupos (que admitem subdivisões). Intuitivamente, esses grupos são:

A. Características constitutivas ou norteadoras das atividades humanas;

B. Qualidades dos métodos/processos empregados;

C. Características dos resultados da ciência.

Nesse último grupo estão as virtudes usualmente discutidas na filosofia da ciência. Elas são tradicionalmente vistas como epistêmicas em vista de apontarem para a verdade, para o conhecimento ou algum outro componente desse conceito, de modo com que sejam indicadores do bom juízo científico. Essa ideia é discutida por Longino (2017, p. 44). De acordo com a autora, o status epistemológico com respeito tanto às virtudes tradicionais na literatura quanto às virtudes alternativas que podem (e têm sido) levantadas em seu contraste, sobretudo na epistemologia feminista, não é evidente. Isto é, essas características não fecham as lacunas entre as evidências e as hipóteses; elas não indicam que uma hipótese virtuosa é verdadeira ou está mais próxima da verdade.

Dentre as virtudes contrastadas pela autora, estão a novidade, a heterogeneidade ontológica, a complexidade ou mutualidade da interação, a aplicabilidade às necessidades humanas correntes e a descentralização do poder ou o empoderamento universal. Em paralelo à adequação empírica, ao invés de epistêmico, o status dessas características (e das tradicionais) parece ser pragmático, ou metodológico, motivo pelo qual a autora utiliza o termo "heurística". Assim, há uma opção por caracterizar todas ou ao menos algumas delas enquanto virtudes pragmáticas desejáveis. Por exemplo, da Costa cita que as teorias, colocadas por ele nos termos de "sistemas cognitivos", podem satisfazer condições de natureza pragmática: "simplicidade, poder explicativo, valor heurístico, coerência com diversas outras teorias científicas, possibilidade em princípio de ser axiomatizado e poder de sistematização da experiência, entre outras" (1999, p. 205).

Ainda sobre esse ponto, uma classificação útil foi colocada por Douglas (2013). A autora argumenta que cada tipo de virtude possui e deve permanecer em seu lugar adequado na atividade científica. Para isso, é preciso esclarecer as bases e as funções dessas virtudes, organizando-as em quatro grupos. Esses grupos são formados juntando um aspecto sobre onde a virtude é aplicada (na teoria per se ou na relação entre a teoria com as suas evidências) com um aspecto sobre como a virtude atua (critérios mínimos da ciência adequada ou desideratos científicos). Assim, a autora argumenta, por exemplo, que a simplicidade e o poder explicativo, quando atuarem como desideratos das teorias per se, não são virtudes epistêmicas - o que não significa que não são características importantes. Sobre a sua proposta, Douglas conclui que se a mesma contribui para o esclarecimento do campo, "então é hora para um esforço renovado em direção a uma teoria qualitativa da inferência científica" (2013, p. 805). Penso que a abordagem Chang (2004) está indo em uma direção similar, inclusive para além das virtudes do Grupo C.

Envolta dessas classificações, está a seguinte moral: um pluralismo epistemológico não precisa trabalhar com as virtudes da ciência da mesma maneira, atribuindo-as o mesmo peso e as mesmas funções. Salientar isso é imprescindível em vista do propósito de "compreender perfeitamente um sentido de justificação hierárquica, sem insistir que essa justificação deva terminar em uma base inabalável ou temer que esteja condenada a um regresso ao infinito" (Chang, 2004, p. 224). Essa hierarquia transparece através das iterações epistêmicas, dos sistemas de práticas. Contudo, vale notar que Chang (2004) sinaliza apenas virtudes do Grupo C na afirmação desse pluralismo em "Inventing Temperature". Ele menciona, por exemplo, os critérios para avaliar a qualidade do vínculo entre teorias e aspectos observacionais colocados por Hempel (quantidade, variedade, 
precisão e evidência). Retoma também a lista de Kuhn das características da mentalidade científica que se pode discutir e optar, mas cujo completo abandono representa o abandono da própria mentalidade científica (exatidão, coerência interna e externa, escopo, simplicidade e fecundidade). Dentre outras, ele apresenta ainda as virtudes pragmáticas desejáveis sinalizadas por Van Fraassen (elegância, simplicidade e poder explicativo).

Porém, em trabalho anterior, Chang afirma que a precisão preditiva (que para ele é sinônimo de adequação empírica) e o poder explicativo são dois objetivos primários da atividade científica - tão antigos quanto a humanidade ela mesma (cf. Chang, 2001, p. 25). Nesse sentido, embora a necessidade de situar a abordagem de Chang (2004) apareça naturalmente através do seu pluralismo epistemológico colocado em "Inventing Temperature", ela recai em uma distinção sobre os propósitos da ciência que remonta ao menos até "How to Take Realism Beyond Foot-Stamping” (2001). Aqui, Chang (2001) argumenta que há uma diferença clara entre a sua proposta e algumas formas de realismo científico, bem como em relação aos projetos empiristas. Em contraste aos últimos, a diferença recai sobretudo no valor atribuído ao que ele denomina por "função mitológica da ciência": o pensamento de que a ciência possui a tarefa de "fornecer compreensão para além da descrição e previsão dos fenômenos" (2001, p. 25). Nesse sentido, Chang (2001) já sinalizava virtudes vinculadas com a adequação empírica de uma teoria e vinculadas com a inteligibilidade dessa teoria dentro de uma tradição.

Para Chang (2001), a valorização da função mitológica da ciência divide projetos empiristas e realistas. Se a função mitológica da ciência não é valorizada, então não há motivos para insistir em um realismo em geral e, segundo Chang, aqui está a postura de van Fraassen, de Duhem e demais filósofos(as) que reivindicam uma atividade científica que não esteja "subordinada à metafísica" (2001, p. 26). Se essa função é valorizada, então há espaço para abordagens realistas da ciência - ponto que é utilizado para promover uma crítica a algumas formas de realismo e que dá início à proposta do seu "realismo ativo", desenvolvido en passant em "Inventing Temperature" (2004) no tema dos princípios ontológicos, mas maturado na década seguinte, em "Is Water $\mathrm{H}_{2} \mathrm{O}$ ?" (2012). ${ }^{15}$

A organização de Douglas (2013) ajuda a compreender o contraste entre o realismo ativo e outras abordagens realistas. No primeiro, uma noção de "verdade" enquanto descrição objetiva para além do observável não é uma virtude científica que atua como critério mínimo na ciência - seja das teorias per se, tampouco da relação entre as teorias e a evidência. O realismo ativo buscará essas virtudes em outros lugares e valores, como em sua função mitológica. Ademais, vale a pena notar também outro sentido em que o tema dos valores da ciência está presente na consideração da "função mitológica da ciência": na afirmação de que van Fraassen (1980) e os demais empiristas não a valorizam, apontando uma diferença entre os papéis epistêmicos e os papéis pragmáticos das virtudes na ciência.

O empirismo construtivo argumenta que aceitar uma teoria requer a crença apenas em alguns dos seus aspectos, distinguindo entre crença e aceitação. Uma virtude epistêmica, assim, é algo que está relacionado com a crença, com a verdade e com a justificação. Uma virtude pragmática pode estar relacionada com a aceitação ou várias outras maneiras de se portar frente ao que a atividade científica faz e do que dela resulta, aos seus objetivos e às suas teorias. Nesse sentido, a explicação e outras virtudes relacionadas com a inteligibilidade da ciência são, para Chang (2001) e ao contrário dos empiristas, desideratos das teorias per se genuinamente epistemológicos. Elas não são, contudo, critérios mínimos da ciência uma vez que, para o pluralismo de Chang (2001), uma teoria científica pode ser empiricamente adequada e não cumprir uma "função mitológica" - caso em que se pode adotar uma postura instrumentalista inofensiva sobre ela, uma vez que a teoria funciona ao prever, mas não explica.

Para van Fraassen (1980), assim como para Longino (2017), a explicação científica e suas virtudes correlatas são muito valiosas, mas o seu valor é independente de serem verdadeiras. Assim como a simplicidade,

15 Sobre as críticas a algumas formas de realismo, cumpre citar a conclusão do próprio autor: "se um sistema de conhecimento for empiricamente bem-sucedido, ele nos ajudará a fazer; se for ontologicamente plausível, nos ajudará a entender; se for ambos, isso é ainda mais maravilhoso. Não está claro o que mais poderíamos razoavelmente exigir ou reivindicar. Insistir em alguma 'verdade' além da utilidade e da inteligibilidade seria apenas pirraça' (Chang, 2001, p. 30). 
não há uma relação direta entre a verdade da teoria e o desempenho da sua função mitológica; motivo pelo qual, desde um ponto de vista empirista, as virtudes relacionadas com ela são razões para aceitar, mas não para crer. A divergência para com Chang (2001), então, é profunda. Ela versa sobre o que pode ser epistemologicamente alcançado pela ciência, sobre a natureza do próprio conhecimento científico, sobretudo em vista do modo como lidam com uma lacuna (semântica ou epistemológica) entre as teorias, as hipóteses e as evidências. Aqui, há ao menos duas saídas para manter o status epistemológico das virtudes (ou das heurísticas): resolver as questões da subdeterminação ou argumentar que elas são epistêmicas mesmo à despeito disso. Diferentes formas de realismo científico optam pela primeira alternativa. Penso que Chang $(2001,2011$, 2012), como já mencionado, visa a segunda.

Sinalizada em "Inventing Temperature" (2004), essa opção tem se tornado mais clara em seus trabalhos posteriores. Como lembra Ravetz (1996, p. 236), as características do conhecimento científico envolvem um (aparente) paradoxo, entre o útil saber efêmero e o conhecimento seguro que dificilmente é alcançado. $\mathrm{O}$ autor argumenta que o quão amplamente a palavra "conhecimento" deve ser utilizada depende dessas exigências, podendo inclusive ser uma questão de convenção. Para além disso, o próprio Ravetz se posiciona: "parece melhor restringir o termo aos resultados que são tão sólidos que sobrevivem [...] tanto quanto vive a estrutura da realidade em cujos termos esses são expressos" (1996, p. 236). Nesse sentido, a enfática distinção empirista entre as virtudes epistêmicas e pragmáticas parece estar no caminho correto. Ravetz, contudo, alarga a discussão: "para uma investigação profunda do conhecimento [...] outros tipos de conhecimento devem ser levados em consideração" (Ravetz, 1996, p. 240). O recente pluralismo de Chang (2011) adota justamente essa saída: as virtudes epistêmicas não estão confinadas às características do saber proposicional. Ao fazê-lo, as virtudes dos Grupos A e B são carregadas junto da sua abordagem.

Visando "uma mudança de foco das proposições para as atividades" (Chang, 2011, p. 208) nas investigações epistêmicas, o autor oferece uma espécie de gramática (no sentido empregado pelo Wittgenstein tardio) para as atividades científicas e elenca os aspectos relevantes a serem abordados por uma epistemologia assim baseada. Em suma, sua agenda investigativa é composta pelos seguintes tópicos (cf. Chang, 2011, p. 217):

(a) Atividade: $\mathrm{O}$ que está sendo realizado?

(b) Propósito: Em vista de quais objetivos?

(c) Agentes primários: Quem está fazendo?

(d) Interlocutores: Para quem / com quem se está fazendo isso?

(e) Princípios: Quais pressupostos ajudam essa atividade a ser inteligível?

(f) Capacidades: O que os agentes devem ser capazes de fazer?

(g) Recursos: Quais ferramentas são necessárias para que essa atividade seja bem-sucedida?

(h) Liberdade: Que tipos de escolhas os agentes podem fazer?

(i) Avaliação: Quem está julgando os resultados e com quais critérios?

Nesse sentido, as virtudes tradicionalmente elencadas na filosofia da ciência, o Grupo C, encontram-se substancialmente os itens (b) e (i) - enquanto os outros itens recorrem às outras características valorativas. Tão importante quanto: a liberdade em se delimitar os propósitos indicam que eles podem estar em qualquer subclassificação do grupo C, mas isso não precisa valer necessariamente para os critérios do item (i). A maneira como essas e outras virtudes se encaixam nas iterações epistêmicas pode ser entendida utilizando como ilustração casos da história metrologia - da ciência das medições e das suas aplicações.

Iniciando pelas virtudes do Grupo $\mathrm{A}$, temos as características que versam sobre os agentes primários e suas capacidades - itens (c) e (f). Tradicionalmente, essas virtudes remontam ao seminal trabalho "A Ciência e a Estrutura Social Democrática" do sociólogo estadunidense Robert Merton (2013 [1962]) sobre o éthos da 
ciência. ${ }^{16}$ Segundo ele, o éthos da ciência constitui normas não necessariamente escritas, mas encontradas nos hábitos e crenças de uma comunidade científica. Exemplos discutidos por ele são o comunalismo e a busca por originalidade. Contudo, as características que guiam as atividades humanas para a produção coletiva de conhecimento ultrapassam a lista do éthos clássico. Elas são ditas epistêmicas por conta de indicarem uma aproximação, ou distanciamento no caso de vícios, da capacidade de se alcançar o conhecimento fiável - sobretudo desde um ponto de vista institucional. Como diz Bunge, trata-se, assim, da ciência ser "um meio de produção com uma modalidade ética bem precisa: não pode haver ciência desonesta, ciência em busca deliberada do erro, ou que evite a crítica, ou que suprima a verdade" (apud Cupani, 2018, p. 218). Então, a honestidade, o cuidado intelectual e a coragem aparecem como características virtuosas vinculadas com as atividades humanas, embora em sentido diferente do que é empregado nos imperativos de Merton (2013 [1962]). ${ }^{17}$

Exemplificando, a metrologia é composta por variados grupos de trabalho que visam a padronização científica através da formulação de documentos de referência. Menciono três deles, os quais receberam versões traduzidas para o português pelo Instituto Nacional de Metrologia, Qualidade e Tecnologia - INMETRO:

- Avaliação de dados de medição: Guia para a expressão de incerteza de medição- JCGM 100: 2008 - GUM. Doravante, GUM (INMETRO, 2012a).

- Vocabulário Internacional de Metrologia (3aed.) - JCGM 200: 2012 - VIM 3. Doravante, VIM 3 (INMETRO, 2012b).

- Avaliação de dados de medição: uma introdução ao "Guia para a expressão de incerteza de medição” e a documentos correlatos - JCGM 104: 2009 - INTROGUM 2009. Doravante, INTROGUM (INMETRO, 2014).

Considere-se, então, o cuidado terminológico e a disposição colaborativa dos grupos de trabalho que formularam e traduziram, por exemplo, o INTROGUM, visando "aumentar o acesso à informação sobre metrologia [com] esforços para atualizá-lo regularmente" (INMETRO, 2012a, p. iii). Menciono também a atenção aos detalhes no campo, sejam eles teóricos ou práticos - como pegar corretamente uma determinada amostra, utilizar as luvas apropriadas para que a sujeira dos dedos não a contamine, o cuidado ao limpar os materiais delicados, etc.

Passando para as virtudes do Grupo B, há uma coleção de características vinculadas aos métodos e processos científicos. Por exemplo, o escopo da aplicabilidade de um procedimento de medição; a confiabilidade instrumental, a capacidade de originar indicações precisas, dentre outras. Mais controverso, pode-se destacar ainda as esperanças tradicionais de que certas ferramentas e instrumentos ampliem a objetividade do resultado por retirarem de cena (com uma espécie de filtragem) certas idiossincrasias e elementos contextuais comprometedores.

Utilizando um exemplo metrológico, o GUM destaca que "o método ideal para avaliar e expressar a incerteza do resultado de uma medição deve ser: universal [...] deve ser aplicável a todas as espécies de medição e a todos os tipos de dados de entrada usados nas medições" (INMETRO, 2012a, p. ix). Esse método utilizará uma grandeza, a qual é tanto parte de um processo quanto um produto científico. Assim, suas virtudes estão no Grupo C:

16 A vigência de um éthos científico é um tema que tem recebido ao menos três tipos de críticas: i) sobre a sua adequação descritiva; ii) sobre sua necessidade e sua suficiência prescritiva; iii) sobre a possibilidade prática do mesmo dada a relação que a ciência mantém com a sociedade. Acerca delas, veja-se Cupani (2018, cap. 9).

17 Embora não apareça na lista dos imperativos de Merton (2013 [1962]), a "coragem", a "iniciativa" e a "criatividade" são características implícitas nas suas normas de busca por originalidade e individualidade. Também nesse sentido, sem coragem não há "ceticismo organizado" ou "independência de juízo", isto é, a resistência em submeter-se demasiadamente à autoridade e à tradição, como lembrado por Bunge (apud Cupani, 2018, p. 218). 
a grandeza real usada para expressar a incerteza deve ser:

internamente consistente: deve ser diretamente derivável dos componentes que para ela contribuem, assim como ser independente de como estes componentes estejam agrupados, ou da decomposição de componentes em subcomponentes; transferível: deve ser possível usar diretamente a incerteza avaliada para um resultado como um componente na avaliação da incerteza de outra medição na qual o primeiro resultado é utilizado. (INMETRO, 2012a, p. ix).

Relacionado a isso, a exatidão dos procedimentos de medida e a sua calibração são casos paradigmáticos aqui. ${ }^{18}$ Como argumentado por Tal (2011), o termo "exatidão" possui ao menos cinco sentidos: metafísico, epistêmico, operacional, comparativo e pragmático. Em sentido metafísico, a exatidão é correlata ao conceito de "verdade", afirmada através de um critério de aproximação entre o valor medido e o seu "valor verdadeiro". De acordo com ele, se essa aproximação envolve um valor verdadeiro no sentido de uma realidade independente dos instrumentos, então ela requer uma visão realista sobre os alvos das medições. ${ }^{19}$ Assim, há um viés metafísico na tendência de se explicar a exatidão em vista dos valores de grandeza verdadeiros e independentes dos métodos. Porém, mesmo com a hipótese de que exista esse valor de grandeza, as medições sempre o alcançam aproximadamente, indicando que não há como reduzir os outros sentidos àquele. Então, na prática, metrologistas lidam com os outros quatro sentidos.

Em especial, a exatidão em sentido pragmático versa sobre o uso dos resultados em um contexto adequado, isto é, para satisfazer certos requerimentos da sua aplicação. Assim, ele atravessa os outros sentidos do termo e não pode ser considerado isoladamente, isto é, sem algum outro sentido associado. Isso ajuda a (re)considerar, por exemplo, algumas das virtudes analisadas por Longino (2017). À parte da adequação empírica, a autora contrasta a aplicabilidade da ciência às necessidades humanas como algo que prima facie se opõe à fecundidade teórica da ciência. Ambas as virtudes são pragmáticas no sentido de que não atuam isoladamente: uma teoria pode ser teoricamente fecunda ou um resultado pode ser frutiferamente aplicável apenas junto de outras características epistêmicas. Nesse sentido, elas estão diretamente relacionadas com o item (d) na agenda de Chang (2011), os interlocutores: para quem / com quem se está fazendo isso.

Pode soar estranho afirmar que o objetivo de fornecer e ampliar uma teoria fecunda esteja relacionado com certos interlocutores, mas isso mostra um aspecto essencial da abordagem da Chang (2004): a importância da tradição científica. Para ele, em primeiro lugar, é dentro de um contexto (sobretudo histórico) que se ressaltam os propósitos científicos - lembrando assim que as iterações ocorrem em um sistema de conhecimento já estabelecido em uma tradição, por exemplo, a metrologia contemporânea. Sobre essa, Crease (2013) explica que definir as unidades de medida por meios cada vez mais constantes, estáveis e regulares, é um antigo objetivo metrológico. Até meados de 2018, a unidade-padrão da massa era definida por referência a um cilindro de platina-irídio, sendo a única dentre as chamadas "grandezas básicas" que não havia sido redefinida nos termos de um fenômeno natural estipulado por uma teoria. Nessa perspectiva, o propósito epistêmico da recente alteração na definição do quilograma possui um sentido de progresso muito claro, similar à acepção kuhniana de preencher lacunas em um puzzle.

Contudo, como devemos entender esse puzzle? A importância de se considerar as capacidades, os recursos, os interlocutores e os princípios pela abordagem de Chang (2011) reiteram que se há um "paradigma” em jogo, de modo algum esse pode ser elucidado apenas em vista da estrutura linguística das teorias

18 De acordo com o VIM 3, a calibração é a "operação que estabelece, sob condições especificadas, numa primeira etapa, uma relação entre os valores e as incertezas de medição fornecidos por padrões e as indicações correspondentes com as incertezas associadas; numa segunda etapa, utiliza esta informação para estabelecer uma relação visando a obtenção dum resultado de medição a partir duma indicação" (INMENTRO, 2012b, p. 27).

19 O GUM esclarece isso na própria definição do "valor verdadeiro": "valor consistente com a definição de uma dada grandeza específica. NOTA 1 É um valor que seria obtido por uma medição perfeita. NOTA 2 Valores verdadeiros são, por natureza, indeterminados. NOTA $3 \mathrm{O}$ artigo indefinido 'um' é usado, preferivelmente ao artigo definido 'o', em conjunto com 'valor verdadeiro' porque pode haver muitos valores consistentes com a definição de uma dada grandeza específica” (INMETRO, 2012a, p. 32). 
científicas. Considerando as capacidades dos agentes científicos, a abordagem de Chang (2011) soa como um prosseguimento das análises de Polanyi (apud Cupani, 2018, p. 62) sobre as negligências com relação às habilidades dos cientistas na produção de conhecimento. Também ao modo de Polanyi (apud Cupani, 2018, p. 75), se há problemas a serem resolvidos, são questões que orbitam o compromisso dos agentes com a busca pelo saber científico dentro de uma tradição, mesmo tratando-se de lacunas teóricas.

Ademais, ao incluir um item para os recursos, o programa de Chang (2011) permite uma aproximação com contribuições advindas da filosofia da tecnologia, como o trabalho de Constant (apud Cupani, 2016, p. 178). Nesse sentido, as virtudes operacionais e o seu aprimoramento fazem parte de um tipo de "paradigma tecnológico". Afinal, a metrologia não é uma ciência desvinculada da tecnologia disponível; pelo contrário, e as questões metrológicas também impulsionam o desenvolvimento tecnológico. Se isso faz sentido, pode-se pensar que as alterações e redefinições das unidades seja um caso de "revolução tecnológica" interno à história da ciência. ${ }^{20}$ Nesse aspecto, o VIM 3 e demais documentos fornecidos no campo são partes determinantes de uma padronização sui generis: que constrói relações entre ciência e tecnologia "normais" - uma tecnociência da padronização. A noção de progresso resultante das alterações nesses padrões dialoga com problemas e virtudes tanto teóricos quanto operacionais, em uma rede de complementos.

Mais uma vez, a abordagem de Chang (2011) assemelha-se aos argumentos de Douglas (2014), para quem o progresso da ciência parece ser um quebra-cabeça originado por conta de as teorias científicas terem figurado nas análises da ciência com certa primazia. De acordo com a autora, é mais fácil compreender em que sentido a ciência progride se a entendermos enquanto uma coleção de atividades dinâmicas, na qual a teorização é um dentre outros aspectos importantes. Exemplificando esse aspecto, o trabalho de Quinn (2017) apresenta, desde um ponto de vista interno ao desenvolvimento metrológico, alguns esclarecimentos sobre a nova definição do quilograma que se encaixam no esquema das iterações epistêmicas. ${ }^{21}$ Além de elucidar como e por quais razões históricas as constantes físicas são visadas para substituir os artefatos nas definições das unidades, Quinn (2017) destaca os desafios tecnológicos na recente alteração. À parte dos detalhes técnicos dos trabalhos com as balanças de watt e com as técnicas de cristalografia de raios-x, que exigiriam um espaço considerável, a ideia de que esses instrumentos permitem realizar aproximadamente as definições é avançada por Quinn (2017) junto de uma visão intuitiva sobre os sentidos em que elas representam um progresso. Assim, Quinn explica que

qualquer definição abstrata de uma unidade levanta a questão de como ela pode ser realizada na prática, ou como as medições podem ser feitas de acordo com a definição. Isso é muito diferente da realização prática de uma definição baseada em um objeto material, onde a realização prática é o próprio objeto. Tradicionalmente, uma unidade era considerada um exemplo particular da grandeza em questão, escolhida para ter um tamanho conveniente, como acontece com os protótipos internacionais do metro e do quilograma (2017, p. 11).

Nesse sentido, (re)definir as unidades é um movimento prático-teórico: uma nova concepção do Sistema Internacional de Unidades - SI.

Junto do item da liberdade salientado na agenda de Chang (2011), Quinn (2017) afirma que é um lucro dessa nova concepção metrológica a permissão para que se utilize qualquer equação física que se considere pertinente para estipular a relação entre uma definição e a sua realização. Quinn (2017) afirma também a

20 Ressaltando-se que "à diferença das revoluções científicas no modelo de Kuhn, que são ao mesmo tempo inovadoras e eliminatórias, as revoluções tecnológicas não necessitam implicar uma seleção radical, não supõem forçosamente uma nova comunidade, e são compatíveis com a continuidade da tecnologia 'normal”' (Cupani, 2016, p. 180). Destaco também que, se há uma revolução tecnológica nesse desenvolvimento metrológico, então ela foi precedida por "anomalias" presumíveis (cf. Cupani, 2016, p. 178): o reconhecimento de que os desempenhos metrológicos fornecidos por padrões naturais são mais seguros, exatos, amplamente aplicáveis, dentre outras características e finalidades.

21 O ponto de vista é dito “interno" por conta de Quinn (2017) ocupar a posição de diretor emérito do Bureau International des Poids et Mesures - BIPM. 
esperança de que desenvolvimentos teóricos e tecnológicos futuros possam proporcionar novas equações que sirvam de referências para outras unidades e procedimentos, os quais poderão modificar a exatidão aproximada das realizações - preenchendo lacunas e aprimorando métodos. Assim, o progresso da ciência, como notado por Douglas (2014), também não se reduzirá apenas ao surgimento de novos e "melhores" artefatos.

Há uma questão que fica, contudo: onde estão os "princípios ontológicos" e para que eles servem nesses cenários? Ou seja, o que a agenda de Chang (2011) espera incluir no item (e). Falarei um pouco mais sobre isso, como fechamento deste artigo. De qualquer modo, espero ter mostrado, até aqui, alguns sentidos em que a abordagem de Chang (2004) tem se situado nos debates sobre os valores da ciência. Penso que Chang (2004) tem se desafiado na formulação de uma filosofia digna de atenção. Falo em desafio, pois, como diz van Fraassen

a filosofia da ciência tenta responder à pergunta 'o que é ciência' exatamente no sentido em que a filosofia da arte, a filosofia do direito e a filosofia da religião respondem à pergunta semelhante sobre seu assunto. [...] para o bem ou para o mal, nossa tradição se concentrou mais na teoria científica do que na própria atividade científica. Nós nos concentramos no produto, e não no objetivo, condições e processos de produção, para traçar uma analogia que já aponta em sua terminologia para o produto como a característica mais saliente. No entanto, todos os aspectos da atividade científica devem ser esclarecidos para que o todo se torne inteligível. (1989, p. 189).

\section{Considerações finais: Metodologias Virtuosas e Plausíveis}

Este trabalho discutiu sentidos em que o projeto epistemológico de Chang adentra o debate sobre os valores da ciência. Para fins de síntese, a metáfora dos marinheiros fornecida por Neurath ajuda a conceber o coerentismo progressivo de Chang. ${ }^{22}$ Como o navio daquele cenário, um sistema inicial de conhecimento já está historicamente construído. Alterações nas partes do navio são válidas em vista de certos objetivos, como aproveitar melhor o vento e, sobretudo, não naufragar. Uma teoria da justificação, assim pretendida, atua sempre sobre um sistema de conhecimento já formulado e que está em desenvolvimento, afinal, como canta Bethânia na epígrafe desse artigo, de que serve a terra à vista se o barco está parado? A questão central nessa metáfora epistemológica é, então, para onde ele está indo (e suas correlatas: como pode ir, para onde queremos que vá, etc.).

Isso mostra alguns dos sentidos em que a questão das virtudes da ciência está no centro do projeto de Chang, mesmo antes, mas sobretudo em "Inventing Temperature" (2004): o seu pluralismo epistemológico caminha naturalmente por esses assuntos. Tal pluralismo pode ser entendido enquanto uma defesa do caráter progressivo, virtuoso e plausível das metodologias científicas situadas em tradições. A questão da plausibilidade versa sobre as asserções de fundo compartilhadas por uma determinada tradição. Como fechamento, vale mencionar brevemente dois aspectos sobre os status das virtudes relacionadas com essas suposições de fundo: a separação entre virtudes epistêmicas e sociais; a constituição ontológica das finalidades epistêmicas.

Os grupos de valores discutidos anteriormente podem ser unificados através da crença de que eles expressam uma "mentalidade científica" - na qual geralmente se excluem valores sociais e normas morais sem vínculo epistêmico aparente, similar ao destacado por Bunge (apud Cupani, 2018, p. 218-2019) sobre o desperdício de recursos. Essa exclusão tem sido criticada por defensores(as) do caráter social das virtudes científicas, por exemplo, Longino (2017). Ao argumentar que as virtudes científicas são mais bem caracterizadas enquanto heurísticas, Longino (2017) explora a consequência de que as mesmas não são apenas finalidades ou características encontradas nos produtos científicos. Ao contrário, elas atuam antes da investigação e delimitam as estratégias investigativas. Para ela,

22 Cumpre informar: "somos como marinheiros que precisam reconstruir seu navio em mar aberto, sem jamais poder desmontá-lo e reconstruí-lo em uma doca seca, com os melhores componentes” (Neurath, 1983, p. 92). 
os padrões públicos que regulam as interações discursivas e materiais de uma comunidade são tanto provisórios quanto subordinados ao objetivo geral da investigação para uma comunidade. A verdade simpliciter não pode ser esse objetivo, uma vez que ela não é suficiente para direcionar a investigação [...]. [Mas] a verdade não está em oposição aos valores sociais, de fato ela é um valor social, no sentido de que ela é uma demanda social de que a investigação científica forneça verdades ao invés de falsidades, mas sua função regulatória é dirigida/mediada por outros valores sociais operativos no contexto de pesquisa. (LONGINO, 2017, p. 51-52).

Nesse aspecto, penso que o pluralismo de Chang (2004) e o pluralismo empirista da autora se aproximam. Acredito que eles estejam de acordo com relação à ideia de que metodologias/heurísticas diferentes satisfazem objetivos cognitivos diferentes e que "se deve fazer a escolha de um modelo que guiará a ação, mas [...] [não] pela exclusão arbitrária das heurísticas alternativas” (Longino, 2017, p. 54). Eles também se aproximam na consideração popperiana de que a crítica, enquanto atitude coletiva, é condição inexorável da produção do conhecimento científico, argumentando que ambientes apropriados devem ser formulados em vista das suas condições efetivas. ${ }^{23}$

Se este trabalho inicia com uma rápida menção ao pensamento de Kuhn para explicitar o tom da discussão, vale ressaltar agora que o debate entre Kuhn e Popper sobre os perigos dogmáticos da mentalidade científica na "ciência normal", são preocupações explícitas no que Chang tem desenvolvido. Como o próprio afirma:

eu sou um daqueles que acreditam que as ideias de Kuhn sobre a ciência normal eram ao menos tão importantes quanto suas ideias sobre revoluções científicas. E eu sinto um grande dilema em relação à ciência normal. Acho que Kuhn estava certo ao enfatizar que a ciência como a conhecemos só pode funcionar se certos fundamentos e convenções forem [...] protegidos [...] e que mesmo as inovações revolucionárias surgem de forma mais eficaz de tal pesquisa ligada à tradição [...]. Mas também penso que Karl Popper estava certo ao sustentar que o incentivo a essa mentalidade fechada na ciência era 'um perigo para a ciência e, de fato, para nossa civilização', uma civilização que muitas vezes olha para a ciência como a forma ideal de conhecimento e até mesmo um guia para a gestão de assuntos sociais. (2004, p. 236- 237).

Assim, o pluralismo epistemológico de Chang (2004) também possui uma coleção de políticas pluralistas e valiosas como norte (cf. Chang, 2012, p. 264), distanciando-se da abordagem de Longino (2017) no peso e no lugar ocupado pelos valores relacionados com a inteligibilidade. ${ }^{24}$ De acordo com Longino,

os dados (medições, observações, resultados experimentais) adquirem relevância evidencial para as hipóteses somente no contexto das suposições de fundo. Estas adquirem

23 Sobre esse ambiente, Longino tem sugerido uma coleção de condições vinculadas com a produção de conhecimento. A própria autora resume quatro dessas condições como segue: "(a) o provimento de foros para a articulação da crítica; (b) a compreensão da crítica (ao invés da mera tolerância); (c) os padrões públicos aos quais são referidas as interações discursivas; (d) a igualdade (ou igualdade moderada) da autoridade intelectual para todos os membros da comunidade [...] o que é necessário não é a integração das virtudes por uma comunidade de pesquisa, mas a tolerância e a interação com a pesquisa guiada por diferentes virtudes teóricas, a construção de comunidades mais amplas ou metacomunidades, caracterizadas pelo respeito mútuo por pontos de vista divergentes, isto é, pelo pluralismo" (Longino, 2017, p. 51-53).

24 Embora não seja uma tese diretamente discutida, a abordagem pragmatista de Chang herda certos elementos, por exemplo de Dewey, que permitem identificar que não há uma dissociação nítida entre fato e valor, tampouco faria sentido que a sua análise filosófica da ciência a deslocasse da sociedade. Isso pode ser interpretado, por exemplo, através da seguinte passagem: "considere o que se deve fazer para definir um termo científico: formular condições formais para seu uso verbal e matemático correto; construir instrumentos físicos e procedimentos para medição, testes padrão e outras manipulações; reunir pessoas em um comitê para monitorar os usos acordados do conceito e desenvolver métodos para aplicar penalidades às pessoas que não aderirem aos usos acordados. De uma só vez, levamos em consideração todos os tipos de coisas inesperadas, desde o operacionalismo até a sociologia das instituições científicas. 'Um metro' ou 'um quilograma' não significaria e não poderia significar o que significa sem toda uma variedade de ações epistêmicas coordenadas pelo International Bureau of Weights and Measures em Paris. Até a semântica é uma questão de fazer, como Wittgenstein e Bridgman nos ensinaram há muito tempo" (Chang, 2020, p. 19). 
estabilidade e legitimidade através da sobrevivência à crítica. As práticas de justificação devem, portanto, incluir não apenas o teste das hipóteses contrastadas aos dados, mas a sujeição das suposições de fundo (raciocínio e dados) à crítica a partir de uma variedade de perspectivas. (LONGINO, 2017, p. 51).

Assim, a discordância não está em haver suposições de fundo, tampouco em empenhar-se em torná-las explícitas. A diferença é que, para Chang (2001), parte desse tema também é ontológico. A sua motivação, assim, consiste em compreender e formular bons meios para se discutir, avaliar e aprimorar também essas compreensões culturais compartilhadas - separando o que são princípios ontológicos das tradições científicas do que são opiniões sobre o mundo. Um episódio marcante na história das medições científicas ajuda a entender o que está em jogo.

Há uma famosa e muito citada fala de Thomson (1889), mais conhecido como Lorde Kelvin, sobre a relação entre mensurabilidade e a produção de conhecimento científico, realizada em 1883 para o Institution of Civil Engineers - ICE. ${ }^{25}$ Para ele, a quantificação, a mensurabilidade e a modelagem eram virtudes genuinamente científicas: bases para o conhecimento científico, bons indicadores desse conhecimento e elementos para decidir entre hipóteses rivais. Algum tempo antes, a despeito de sua elegância matemática, a mensurabilidade ainda não era uma virtude da teoria eletromagnética de Maxwell. Contudo, a história do telégrafo e da corrente de deslocamento na propagação eletromagnética proposta por Maxwell é bem conhecida. À época, Lorde Kelvin considerava a proposta de Maxwell não apenas incomensurável, mas também ininteligível. Essa última crença o levou a duvidar de que a luz era uma onda eletromagnética mesmo quando Maxwell apontou as medições proporcionais para as unidades relevantes. Ele "não podia aceitar a corrente de deslocamento, ele considerava as equações de Maxwell como uma quimera altamente enganosa" (Smith e Wise, 1889, p. 460). Uma moral por trás dessa história é explicitada por Gooday: "[nesse caso] a inteligibilidade da física foi mais importante para Thomsom do que a mensurabilidade" (2004, p. 4).

Considerar as hipóteses de fundo, assunções e princípios tácitos, é tornar explícito o que atua na investigação científica para além ou à despeito da adequação empírica, os elementos relacionados com a inteligibilidade. De acordo com Chang (2001), faz parte da história da ciência e do seu desenvolvimento que críticas sejam feitas mesmo às teorias empiricamente adequadas. As relutâncias de Lorde Kelvin em manter as suas convicções no episódio do telégrafo, à época vista por FitzGerald como um claro sinal de dogmatismo, fazem parte de um código de conduta sobre como os seres humanos se relacionam com os seus próprios projetos, crenças e sonhos - uma busca que admite paulatinas transformações. ${ }^{26}$ Mas não apenas isso, para além de crenças pessoais, estão em cena hipóteses não empíricas que atribuem sentido à própria atividade científica, as quais também podem ser alteradas. ${ }^{27}$ É sobre esse tema que Chang coloca a questão e aponta uma resposta: "como esse comportamento pode ser justificado? O seu criticismo está baseado no seu

25 Trata-se do seguinte parágrafo: "quando você pode medir aquilo sobre o que está falando e expressá-lo em números, você sabe algo sobre isso; mas quando você não pode medi-lo, quando você não pode expressá-lo em números, seu conhecimento é de um tipo insuficiente e insatisfatório: pode ser o início do conhecimento, mas em seu pensamento você pouco avançou ao estágio da ciência, qualquer que seja o assunto" (Thomson, 1889, p. 73 - 74).

26 Smith e Wise contam que "da perspectiva de FitzGerald, no entanto, foi Thomson quem ameaçou o empreendimento científico com seu compromisso 'reacionário’ com um éter elástico-sólido. FitzGerald também buscou modelos dinâmicos e [...] desenvolveu um cujos elementos obedeciam às equações de Maxwell. [...] ele mostrou como os deslocamentos elétricos podem ser considerados como 'mudanças na estrutura dos elementos do éter, e não deslocamentos reais dos elementos', como nas teorias de sólidos elásticos. FitzGerald insistia em sua natureza puramente heurística [...]. Ele acusou Thomson de dogmatismo: 'eu também acho que Sir Wm. Thomson, não obstante suas declarações cautelosas sobre o assunto, está emprestando sua autoridade esmagadora a uma visão do éter que não é justificada por nosso conhecimento atual e que pode levar aos mesmos resultados infelizes em atrasar o progresso da ciência que surgiram do estudo de Sir Isaac Newton em defesa igualmente protegida da teoria corpuscular da óptica”' (1989, p. 461).

27 Vale lembrar que a modelagem, a mensurabilidade e a quantificação de fato eram virtudes primordiais para o modo como Kelvin entendia a ciência, motivo pelo qual é preciso destacar que na data da sua famosa palestra ele considerava que "a velocidade da luz e a velocidade das ondas eletromagnéticas estavam 'provavelmente fisicamente conectadas"' (Gooday, 2004, p. 4). Para mais detalhes dessa história, sugiro ver-se o capítulo 12 de "Energy and empire: A Biographical Study of Lord Kelvin" - de Smith e Wise (1989). 
comprometimento firme com alguns princípios ontológicos" (2001 p. 11). É também por esse motivo que esses princípios possuem um lugar em sua agenda - o item (e); o qual está diretamente relacionado com as suas críticas às posturas realistas que visam fornecer teorias da verdade para além da adequação empírica.

Chang propõe que se deve "enfrentar o fato de que não podemos saber se obtivemos a verdade objetiva sobre o mundo" (2018, p. 31), buscando um outro tipo de realismo, um "realismo ativo" que vise o desenvolvimento científico. Em vista do famoso argumento de Putnam sobre o realismo ser a única postura filosófica que não atribui ao sucesso da ciência um caráter acidental, Chang (2016) questiona o que se entende por "sucesso" da ciência. Dellsén (2018) afirma que há quatro teses no atual debate sobre como a ciência se desenvolve: i) se aproximando da verdade; ii) a eficácia na solução de problemas; iii) por acúmulo de conhecimento e, finalmente, iv) aumentando a compreensão científica. Ao invés de um ponto isolado, Chang (2001) argumenta em favor de uma abordagem pluralista: a ciência se desenvolve através de modificações práticas, teóricas e ontológicas em suas iterações epistêmicas. Como já ressaltado, esse caráter ontológico, contudo, é distinto da busca por descrições objetivas do que é inobservável, ainda que recursos como a inferência à melhor explicação em vista da "plausibilidade ontológica" sejam utilizados.

Nesse contexto, "plausibilidade ontológica" significa a satisfação de certos princípios que estão para além da adequação empírica e são valorizados por uma comunidade científica em um determinado momento histórico. Tais princípios formam uma coleção de condições que tornam as práticas inteligíveis: aquelas normas ou regras discerníveis que atuam no pano de fundo e atribuem sentido ao que se está fazendo. Chang (2001, 2009) apresenta e discute diversos desses e as funções que eles desempenharam em episódios ao longo da história da ciência, distinguindo entre sistemas simples e complexos. Em sua forma simples, um sistema é dado pelo par: princípio ontológico - atividade epistêmica. O par formado pela atividade de contar e o princípio do ser discreto é um bom exemplo. Outros exemplos são: a explicação e princípio da razão suficiente; a observação e o princípio da externalidade; a identificação e o princípio de ser discernível. Caracterizando esses princípios, Chang (2009) argumenta que eles não versam necessariamente sobre o mundo. Por exemplo, o ser discreto não é uma característica dos objetos per se, mas algo que o indivíduo assume para que a atividade de contar faça sentido. Eles também são condicionais, é apenas se alguém vai contar que o princípio precisa ser assumido. Ainda assim, eles são constitutivos, requeridos, ou "pragmaticamente necessários": a sua ausência torna a prática ininteligível.

Nesse sentido, esses princípios também atuam como peças nas iterações epistêmicas. Para exemplificar, volto ao cenário do problema de coordenação na termometria - um pouco antes da tabela mencionada anteriormente, entre 1730 e 1785 . O caso é o mesmo: termômetros diferentes discordavam entre si, mesmo quando graduados de maneira similar, isto é, marcados em vista dos pontos de fusão e ebulição da água. Então, para cada termômetro havia uma espécie de escala. O problema não é apenas como decidir entre eles, mas os próprios critérios para isso. Como saber quais termômetros informam as regularidades relevantes que podem atuar na compreensão do comportamento dos próprios termômetros? Analisando a solução de Regnault para o caso, Chang (2001) argumenta que ele utilizou de um desses princípios ontológicos, relacionado com o que o autor chama de "testing-by-overdetermination": o princípio do valor singular.

O princípio do valor singular é um dentre vários que atuam nas atividades de medir e em seus testes. Ele diz que, se um alvo é mensurável, então há apenas um único valor a ser atribuído a ele em uma mesma situação. Quando Regnault examinou os vários tipos de termômetros da época - variando concentrações de álcool, alterando o tipo de vidro nos termômetros de mercúrio e modificando os termômetros de gás da época - ele dispensou aqueles que não fornecem indicações coerentes na mesma situação. Essa prática é justificada apenas com a assunção tácita do princípio do valor singular: a repetição do mesmo termômetro tem que informar a mesma indicação, bem como termômetros do mesmo tipo em uma mesma situação devem fazê-lo. Foi através dessa análise prática e operacional, a qual testa a plausibilidade das indicações dos tipos de termômetros, que Regnault obteve indicações comparáveis utilizando instrumentos com gás atmosférico - algo não usual na época - termômetros que posteriormente foram utilizados nos seus famosos experimentos sobre o calor. 
O progresso científico, assim, ocorre através da colocação e substituição de múltiplas peças, com diferentes funções e naturezas em um "processo em que estágios sucessivos de conhecimentos [...] são criados para aprimorar o alcance dos objetivos epistêmicos" (Chang, 2004, p. 45). Embora exatidão e precisão sejam virtudes epistêmicas norteadoras das medições, nem sempre elas estão disponíveis. Mais do que isso, para Chang (2004), a história da sua busca é também a história da busca por inteligibilidade. Talvez, ao fundo, estejamos escavando a história do compromisso com o saber, marca do que Chang (2012) tenta propor ao se dizer "realista". Sobre esse realismo, vale lembrar que a abordagem do autor está em desenvolvimento. Em relação a isso, ele coloca a seguinte esperança:

quando o coerentismo pragmatista esboçado aqui estiver totalmente desenvolvido, as pessoas comprometidas com uma compreensão realista da prática científica serão capazes de reivindicar as noções de verdade e realidade, que são na verdade termos úteis na linguagem comum, assim como no discurso científico. Isso vai ajudar a tarefa de fazer estudos detalhados e sistemáticos da prática científica, sem prescindir de preocupações com a verdade e a racionalidade. (CHANG, 2016, p. 120). ${ }^{28}$

Sobre o que virá, o objetivo deste artigo terá sido ultrapassado se o(a) leitor(a), assim como eu, estiver com sintomas de curiosidade intelectual.

\section{Referências Bibliográficas}

SMITH, Crosbie; WISE, Matthew N. Energy and Empire: A Biographical Study of Lord Kelvin. Cambridge: Cambridge University Press, 1989.

TAL, Eran. How Accurate Is the Standard Second? Philosophy of Science, v. 78, n. 5, p. 1082-1096, 2011.

TAL, Eran. Old and New Problems in Philosophy of Measurement. Philosophy Compass, v.8, p. 1159-1173, 2013.

TAL, Eran. Measurement in Science. In: ZALTA, E. (ed). The Stanford Encyclopedia of Philosophy, 2020. Disponível em: https://plato.stanford.edu/archives/fall2020/entries/measurement-science/. Acesso em: 04 jan. 2021.

THOMSON, William. Popular Lectures and Addresses. vol. 1. London: MacMillan, 1889.

Van FRAASSEN, Bas. The Scientific Image. Oxford: Clarendon Press, 1980.

Van FRAASSEN, Bas. Laws and Symmetry. Oxford: Oxford University Press, 1989.

Van FRAASSEN, Bas. From a View of Science to a New Empiricism. In: MONTON, B. (org.). Images of Empiricism: Essays on Science and Stances, with a Reply from Bas C. van Fraassen. Oxford: Oxford University Press, 2007, p. 337-383.

Van FRAASSEN, Bas. Scientific Representation: Paradoxes of Perspective. Oxford: Oxford University Press, 2008.

VAZ, Rafael. As teses de Hacking e Chang em favor do realismo: uma breve introdução. In: DUARTE, A.; GUITARRARI, R. (org.). Lógica e Racionalidade Científica. Seropédica: PPGFIL-UFRRJ, 2019, p. 98-111.

WEISBERG, Michael; NEEDHAM, Paul; HENDRY, Robin. Philosophy of Chemistry. In: ZALTA, E. (ed). The Stanford Encyclopedia of Philosophy, 2019. Disponível em: https://plato.stanford.edu/archives/spr2019/entries/chemistry/. Acesso em: 05 jan. 2020.

28 No meu entendimento, Longino (2017), van Fraassen (2008) e demais empiristas não "prescindem" de preocupações com a verdade, tampouco com a racionalidade da ciência. A questão, me parece, está no framework geral que a filosofia da ciência tem assumido. Aqui, mesmo que a investigação linguística não seja sempre o foco das teses de Longino (2017), a abordagem da autora é frequentemente apoiada na tese da subdeterminação, a qual ela se refere enquanto uma "lacuna semântica". 